\title{
Role of Metal Oxide Nanostructures in Extracellular pH Regulations
}

\author{
Aleksandr S. Lozhkomoev ${ }^{1, a)}$ \\ ${ }^{1}$ National Research Tomsk Polytechnic University, Lenin Avenue 30, Tomsk, 634050 Russia \\ ${ }^{\text {a) }}$ Corresponding author: asl@ispms.tsc.ru
}

\begin{abstract}
A research area of great promise is the cancer treatment by regulating microenvironmental parameters of tumor cells using $\mathrm{MgO}$ and $\mathrm{AlOOH}$. Magnesium hydroxide and aluminum oxyhydroxide (boehmite) are in the form of nanoplates and nanosheets. The morphology, structure, phases and electrokinetic properties of synthesized samples are analyzed using complex physical and chemical methods. We study how the $\mathrm{pH}$ of the culture medium - different when in contact with synthesized nanoplates - affects the viability of tumor cells. It is shown that $\mathrm{MgO}$ is more efficient in decreasing the tumor cell viability than $\mathrm{AlOOH}$. In the case of magnesium hydroxide, the $\mathrm{pH}$ of the culture medium increases to 10.1 ; in the case of boehmite, to 7.7 .
\end{abstract}

\section{INTRODUCTION}

Recent trends in medicine are towards increased use of nanomaterials and nanotechnology [1-3]. A direction for future research is to find new ways of influencing the extracellular environment through regulation of their microenvironmental parameters (acidity, ion balance, etc.) [4-6]. This is due to the fact that the ionic state of the extracellular space governs the life activity and cell viability [7]. Integral characteristics reflecting the ionic state of biological fluids, extracellular fluid included, are the $\mathrm{pH}$ value [8-10]. For example, due to altered metabolism tumor cells create an acidic environment around them, which is characterized by low pH relative to normal cells [11].

Nanoobjects show promise for adjusting $\mathrm{pH}$ of the cell microenvironment, as being capable of releasing $\mathrm{OH}-$ ions into the extracellular space or absorbing $\mathrm{H}+$. Various methods exist for synthesizing nanoobjects based on aluminum and magnesium oxyhydroxides. It was previously shown [12-16] that pseudoboehmite nanosheets can be easily synthesized with the use of electro-exploded aluminum nanopowders [17, 18]. Other synthesis methods allow a production of aluminum oxides of different phase composition and structure: nanowhiskers, nanoflakes, nanowires, nanofibers, nanorods, nanotubes, nanosheets, nanoplates, etc. [19-25]. As for nanostructured particles based on magnesium hydroxide, they can be synthesized in the form of hexagonal nanoplates [26, 27], flower-like nanostructures [28], and nanorods [29].

The tumor cell cytotoxicity of aluminum oxyhydroxide nanostructures has been earlier studied [30, 31]. It was shown that these nanostructures have a cytotoxic effect on tumor cells, but the mechanism is not known with assurance. It was proposed elsewhere that one possible mechanism of antitumor activity is a changed ionic balance of the intercellular environment [32]. Zhang et al. investigated the cytotoxic effect of $\mathrm{MgO}$ nanoparticles and demonstrated that the cell viability reduction is due to increasing $\mathrm{pH}$ of the extracellular medium [33, 34]. Tsukanov and Psakhie revealed that magnesium-aluminum double hydroxides can adsorb molecules of the extracellular environment [35]. This can interfere with normal nutrition and lead to their death.

In the present work we synthesize nanostructures based on aluminum oxyhydroxide and magnesium oxide, which are capable of changing $\mathrm{pH}$ of the cell microenvironment. We also study their cytotoxicity against tumor cells. 


\section{MATERIALS AND METHODS}

Nanostructures based on aluminum oxyhydroxide and magnesium hydroxide are synthesized by hydrolysis of aluminum and magnesium alkoxides, as well as of their mixtures. Alkoxides are prepared by dissolving aluminum and magnesium turnings in butanol. A $3.00 \mathrm{~g}$ sample of metal is placed in a $250 \mathrm{ml}$ conical flask. When synthesizing mixtures with different metal contents, the sample weights are $1.00 \mathrm{~g}$ of $\mathrm{Al}$ and $2.00 \mathrm{~g}$ of $\mathrm{Mg}$ as well as $1.50 \mathrm{~g}$ of $\mathrm{Al}$ and $1.50 \mathrm{~g}$ of $\mathrm{Mg}$. Samples are filled with $200 \mathrm{ml}$ of butanol and boiled under reflux until complete dissolution of metals, with constant stirring. Heating and stirring is performed by a MSH-300 magnetic stirrer with a hot plate (Biosan, Latvia). After dissolving, prepared alkoxides are slowly poured into a container with double distilled water $500 \mathrm{ml}$ in volume heated to $60^{\circ} \mathrm{C}$ with constant stirring by the MM-1000 overhead stirrer (Biosan, Latvia). The resulting suspension is stirred for $5 \mathrm{~min}$, after which the precipitate is collected by filtration and dried at $200^{\circ} \mathrm{C}$ for 4 hours.

The products are characterized by powder X-ray diffraction (XRD) patterns using a Shimadzu XRD 7000 diffractometer (Shimadzu Corporation, Japan) with $\mathrm{CuK}_{\alpha}$ radiation. Transmission electron microscopy (TEM) is performed on a JEM-2100 electron microscope (JEOL, Japan). The distribution of elements in particles is evaluated in an integrated microscope with the X-Max energy dispersive X-ray spectrometer (EDS) (Oxford Instruments, United Kingdom).

Toxic effects of synthesized nanostructures are determined by the MTT assay for MDA (American Type Culture Collection) and PyMT (primary cells isolated from mice tumors) cell lines. Cells are preliminary inoculated in 96-well plates with 7.500 cells per well. They are cultured in a nutrient medium for 24 hours at a temperature of $37 \pm 1{ }^{\circ} \mathrm{C}$ and $5 \% \mathrm{CO}_{2}$. After incubation, the medium is removed and cells are twice washed with DPBS solution.

Cytotoxicity is determined by use of nanostructure suspensions in the cell medium at the concentrations $10,5,1$, $0.5,0.1,0.05,0.01$, and $0.001 \mathrm{mg} / \mathrm{ml}$.

Cells with nanostructures are incubated at a temperature of $37 \pm 1{ }^{\circ} \mathrm{C}$ and $5 \% \mathrm{CO}_{2}$ for 24 hours. For the MTT assay, the culture medium is removed and cells are washed twice with DPBS solution. Each well is further added with $100 \mu \mathrm{l}$ of the culture medium and $10 \mu \mathrm{l}$ of MTT solution at the concentration $5 \mathrm{mg} / \mathrm{ml}$. The incubation with MTT solution is carried out for 2 hours at a temperature of $37 \pm 1{ }^{\circ} \mathrm{C}$ and $5 \% \mathrm{CO}_{2}$. After incubation, the medium is removed and each well is added with $100 \mu \mathrm{l}$ of dimethylsulfoxide. After $15 \mathrm{~min}$, the optical density is determined with the Tecan Infinite M1000 PRO tablet spectrophotometer (Tecan, Groding, Austria) at a wavelength of $570 \mathrm{~nm}$. The percentage of living cells is calculated relative to optical densities of the test and control samples.

To estimate how synthesized nanostructures affect acidic properties of the EMEM cell culture medium (Minimum Essential Medium Eagle), we determine its $\mathrm{pH}$ variation in time at the concentration of synthesized nanostructures $5.00 \mathrm{mg} / \mathrm{ml}$ with a Multitest IPL-103 pH meter (Semico, Russia).

\section{RESULTS AND DISCUSSION}

The synthesis of metal oxides and hydroxides using alkoxides is one of the methods for producing high-purity materials [36-38] as well as their mixtures [39]. Hydrolysis of aluminum and magnesium butoxide provides a synthesis of 2D nanostructures (Fig. 1).

Hydrolysis of Al butoxide results in crumpled nanosheets of aluminium oxyhydroxide $2-5 \mathrm{~nm}$ thick. Hydrolysis of magnesium butoxide produces nanoplates up to $400 \mathrm{~nm}$ in size and $10-30 \mathrm{~nm}$ in thickness.

As for hydrolysis of different aluminum and magnesium alkoxide mixtures, their products are characterized by a similar morphology and present porous agglomerates of randomly distributed nanosheets $2-5 \mathrm{~nm}$ thick (Fig. 2). The EDS analysis and mapping shows that $\mathrm{Mg}$ and $\mathrm{Al}$ are uniformly distributed over particles, and the quantitative contents of metals in particles corresponds to their stoichiometry in alkoxide mixtures.

According to the X-ray diffraction analysis (Fig. 3), the hydrolysis products of aluminum butoxide and magnesium butoxide are pseudoboehmite and magnesium oxide, respectively. Hydrolysis of alkoxides results in a mixture of pseudoboehmite and magnesium oxide. Note that the XRD pattern of hydrolysis products of aluminum and magnesium alkoxides in the ratio 1:1 reveals a strong broadening of $\mathrm{AlOOH}$ and $\mathrm{MgO}$ reflexes as well as a reduction of their integral intensities. These points to the absence of the long-range order in the atomic arrangement and to the amorphous structure of a sample. 


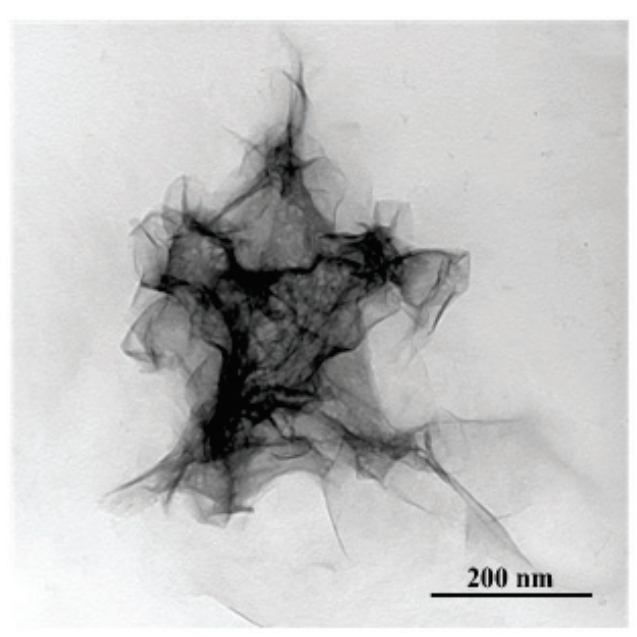

(a)

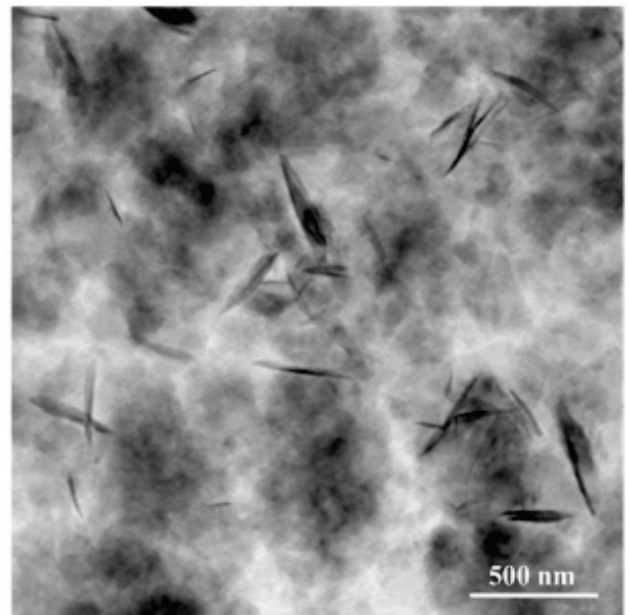

(b)

FIGURE 1. TEM images of Al oxyhydroxide (a) and magnesium oxide (b)

Thus, hydrolysis of aluminum and magnesium alkoxides provides 2D nanostructures of pseudoboehmite and magnesium oxide. The hydrolysis products of alkoxide mixtures are agglomerates of nanosheets of pseudoboehmite and magnesium oxide with their uniform distribution over particles.

Synthesized nanostructures have various acid-base properties and change $\mathrm{pH}$ of the cell culture medium to a different extent (Fig. 4).

As seen from Fig. 4, synthesized nanostructures increase $\mathrm{pH}$ of the cell culture medium to a different extent. Pseudoboehmite raises the $\mathrm{pH}$ of the medium from $\mathrm{pH} 7.2$ to $\mathrm{pH} 7.7$; the pseudoboehmite and magnesium oxide mixture in the mass ratio $1: 1$, to $\mathrm{pH} 8.6$; the pseudoboehmite and magnesium oxide mixture in the ratio $1: 3$, to pH9.4; and magnesium oxide, to $\mathrm{pH} 10.1$. Thus, synthesized nanostructures alter $\mathrm{pH}$ of the cell culture medium to a different extent and can be used to estimate the effect of $\mathrm{pH}$ of the cell microenvironment on their viability.
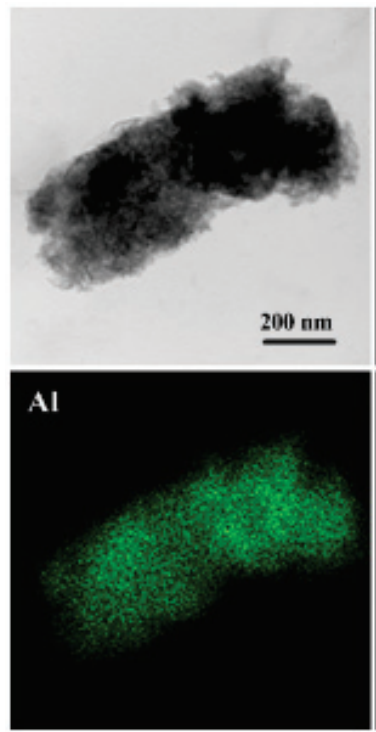
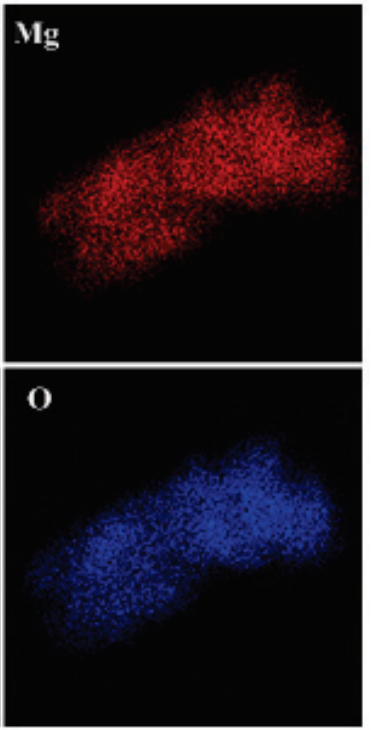

(a)
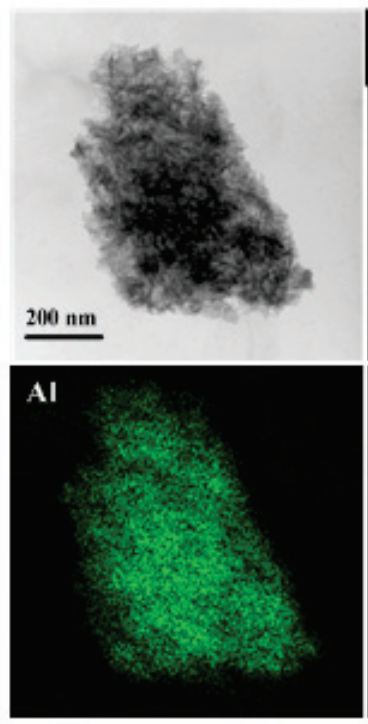

(b)
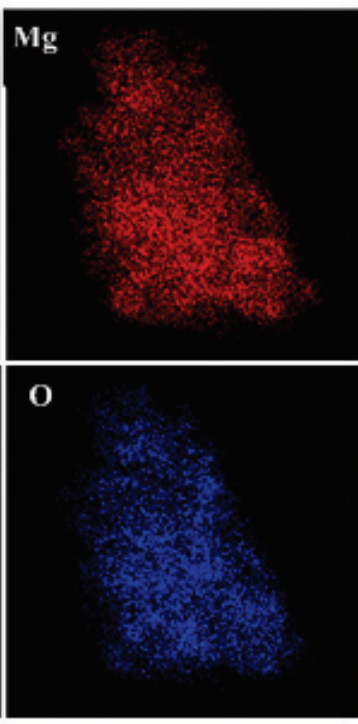

FIGURE 2. TEM images and EDS analysis of mixtures of $\mathrm{Al}$ oxyhydroxide and $\mathrm{Mg}$ oxide in the mass ratio $1: 1$ and $1: 3$, respectively 


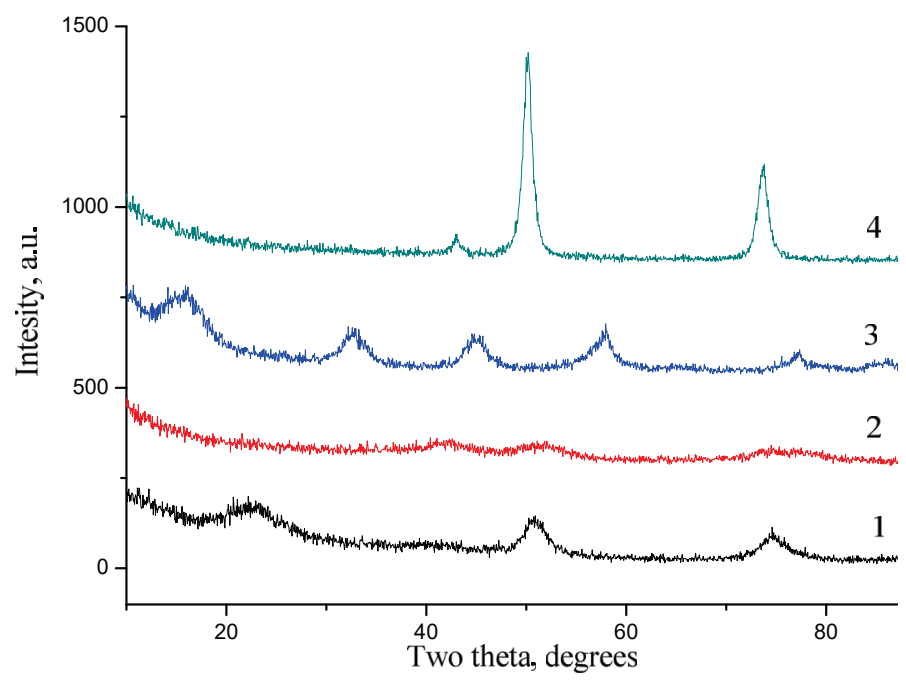

FIGURE 3. XRD pattern of hydrolysis products of aluminum and magnesium alkoxides in the mass ratio $1: 3(1)$, in the mass ratio $1: 1$ (2), aluminum alkoxide (3), magnesium alkoxide (4)

Figure 5 presents the viability of MDA and PyMT tumor cells as a function of concentration of synthesized nanostructures. Figure 5 illustrates the cytotoxic effect of synthesized nanostructures starting at the concentration 1 $\mathrm{mg} / \mathrm{ml}$ and increasing at higher concentrations. Thus, the largest cytotoxic effect is caused by magnesium oxide; the smallest effect, by pseudoboehmite. At the nanostructure concentration from $5 \mathrm{mg} / \mathrm{ml}$, the cytitoxicity and magnesium oxide content show clear correlation. We can thus assume that one of the governing factors for tumor cell vitality is a $\mathrm{pH}$ of their microenvironment. It should also be noted that the synthesized nanostructures have rather large dimensions to penetrate into cells $[40,41]$ and therefore the toxic effect would depend primarily on properties of their surfaces. The basic mechanism of the cytotoxic effect of the synthesized nanostructures is presumed to be a change in the cell membrane potential due to increasing $\mathrm{pH}$ of the extracellular medium and consequently a metabolic disorder.

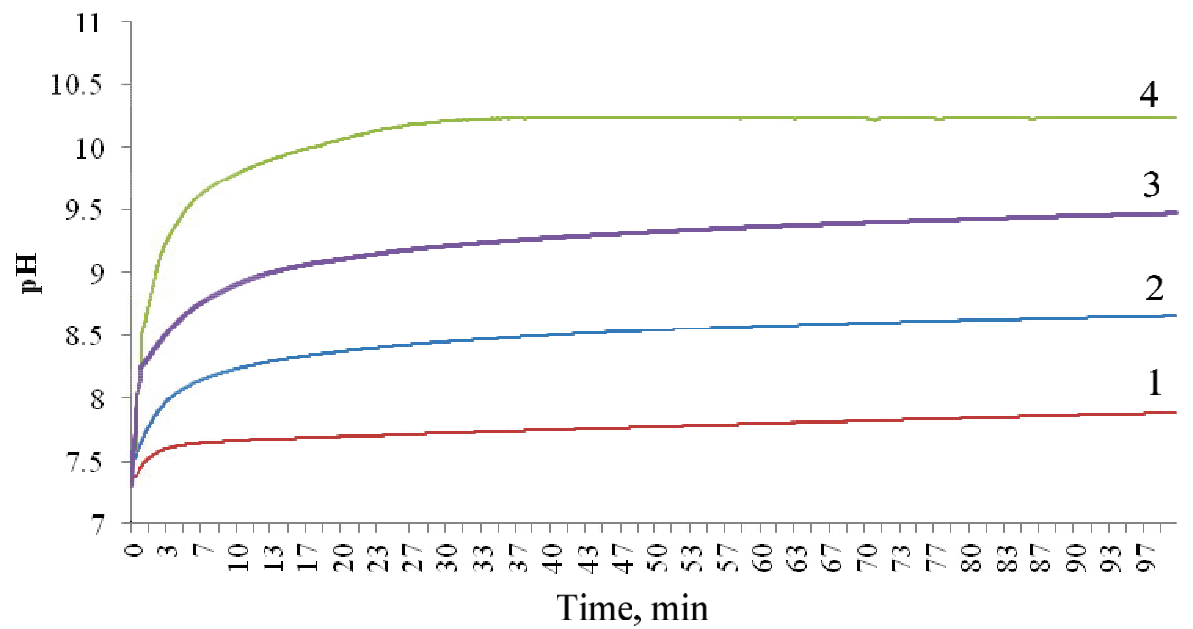

FIGURE 4. Change in $\mathrm{pH}$ of the EMEM culture medium in the presence of synthesized nanostructures at a concentration of $5 \mathrm{mg} / \mathrm{ml}$ : pseudoboehmite (1), pseudoboehmite and magnesium oxide mixture in the mass ratio $1: 1(2)$, in the mass ratio $1: 3(3)$, magnesium oxide (4) 


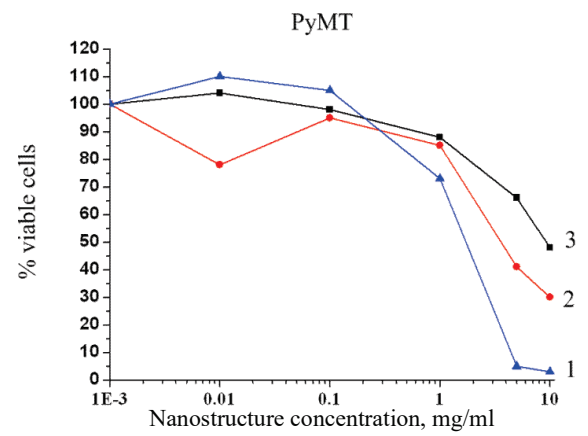

(a)

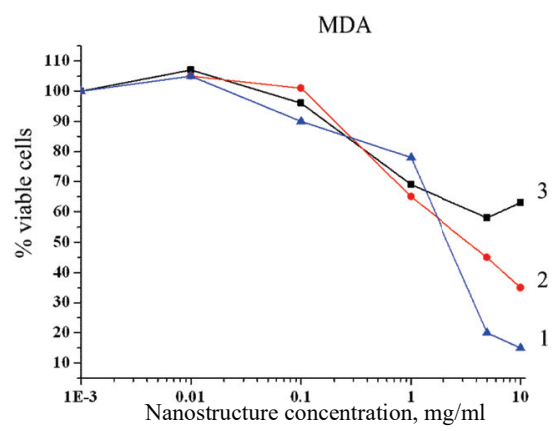

(b)

FIGURE 5. Cytitoxicity dependent on $\mathrm{Mg}(\mathrm{OH})_{2}(1), 1 \mathrm{Al}-1 \mathrm{Mg}$ hydroxide (2), and $\mathrm{AlOOH}$ (3) for PyMT (a) and MDA (b) cell lines

\section{CONCLUSION}

Hydrolysis of aluminum and magnesium alkoxides and their mixtures provides a synthesis of 2D nanostructures of pseudoboehmite and magnesium oxide. It is found that hydrolysis of alkoxide mixtures results in agglomerates of nanosheets with a uniform distribution of $\mathrm{Al}$ and $\mathrm{Mg}$ over particles, in doing so the metal mass ratio in agglomerates corresponds to their mass ratio in the alkoxide mixture. The synthesized nanostructures can alter $\mathrm{pH}$ of the cell culture medium to a different extent. By the example of MDA and PyMT cell lines, it is found that all synthesized nanostructures have a cytotoxic effect at the concentration $1 \mathrm{mg} / \mathrm{ml}$. Pseudoboehmite has the smallest cytotoxicity; magnesium oxide, the largest cytotoxicity.

The results derived show that this approach allows a synthesis of nanostructures capable of changing $\mathrm{pH}$ of the cell microenvironment in the specified range. The synthesized nanostructures show promise for antitumor therapy, either alone or in combination with standard chemotherapy, by potentiating their action through metabolic disorder of cells.

\section{ACKNOWLEDGMENTS}

This work has been done with the financial support of the Russian Science Foundation (Grant No. 14-23-00096). Electron microscopy and X-ray structural studies were performed using the equipment of the Nanotech CUC of the ISPMS SB RAS. Cell studies were conducted in the Jozef Stefan Institute (Slovenia).

The study reported in this article was conducted according to accepted ethical guidelines involving research in humans and/or animals and was approved by an appropriate institution or national research organization. The study is compliant with the ethical standards as currently outlined in the Declaration of Helsinki. All individual participants discussed in this study, or for whom any identifying information or image has been presented, have freely given their informed written consent for such information and/or image to be included in the published article.

\section{REFERENCES}

1. G. Mikhaylov, D. Klimpel, N. Schaschke, U. Mikac, M. Vizovisek, M. Fonovic, V. Turk, B. Turk, and O. Vasiljeva, Angew. Chem. Int. Ed. 53(38), 10077-10081 (2014).

2. G. Mikhaylov, U. Mikac, A. A. Magaeva, V. I. Itin, E. P. Naiden, I. Psakhye, and M. Bogyo, Nature Nanotechnology 6(9), 594-602 (2011).

3. N. V. Kirilova, A. N. Fomenko, and M. S. Korovin, Application of VitaVallis dressing for infected wounds, AIP Conf. Proc. 1688, 030018 (2015).

4. J. A. Burger, P. Ghia, A. Rosenwald, and F. Caligaris-Cappio, Blood. 114(16), 3367-3375 (2009).

5. J. A. Burger, Current Opinion Oncology 24(6), 643-649 (2012).

6. V. A. Chubenko, Prakt. Onkolog. 8(4), 228-234 (2007). 
7. F. Danhier, O. Feron, and V. Preat, J. Controlled Release 148(2), 135-146, (2010).

8. N. Puvvada, S. Rajput, B. N. P. Kumar, S. Sarkar, S. Konar, K. R. Brunt, R. R. Rao, A. Mazumdar, S. K. Das, R. Basu, P. B. Fisher, M. Mandal, and A. Pathak, Sci. Rep. 5, 11760 (2015).

9. I. F. Robey, B. K. Baggett, N. D. Kirkpatrick, D. J. Roe, J. Dosescu, B. F. Sloane, A. I. Hashim, D. L. Morse, N. Raghunand, R. A. Gatenby, and R. J. Gillies, Cancer Res. 69(6), 2260-2268 (2009).

10. D. M. Prescott, H. C. Charles, J. M. Poulson, R. L. Page, D. E. Thrall, Z. Vujaskovic, and M. W. Dewhirst, Clinical Cancer Res. 6(6), 2501-2505 (2000).

11. R. A. Cardone, V. Casavola, and S. J. Reshkin, Nat. Rev. Cancer 5(10), 786-795 (2005).

12. O. V. Bakina, N. V. Svarovskaya, E. A. Glazkova, A. S. Lozhkomoev, E. G. Khorobraya, and M. I. Lerner, Adv. Powder Technol. 26(6), 1512-1519 (2015).

13. A. S. Lozhkomoev, E. A. Glazkova, N. V. Svarovskaya, O. V. Bakina, S. O. Kazantsev, and M. I. Lerner, AIP Conf. Proc. 1683, 020128 (2015).

14. A. S. Lozhkomoev, E. A. Glazkova, N. V. Svarovskaya, O. V. Bakina, S. O. Kazantsev, and M. I. Lerner, AIP Conf. Proc. 1683, 020127 (2015).

15. O. V. Bakina, E. A. Glazkova, N. V. Svarovskaya, A. S. Lozhkomoev, E. G. Khorobraya, and S. G. Psakhie, AIP Conf. Proc. 1623, 35 (2014).

16. A. S. Lozhkomoev, E. A. Glazkova, O. V. Bakina, M. I. Lerner, I. Gotman, E. Y. Gutmanas, S. O. Kazantsev, and S. G. Psakhie, Nanotechnology 27, 205603 (2016).

17. M. I. Lerner, E. A. Glazkova, A. S. Lozhkomoev, N. V. Svarovskaya, O. V. Bakina, A. V. Pervikov, and S. G. Psakhie, Powder Technol. (2016).

18. S. G. Psakhie, K. P. Zolnikov, D. S. Kryzhevich, A. V. Abdrashitov, and M. I. Lerner, Phys. Mesomech. 13(3), 184-188 (2010).

19. J. Li, W. Li, X. Nai, S. Bian, X. Liu, and M. Wei, J. Mater. Sci. 45(1), 177-181 (2010).

20. X. Y. Chen and S. W. Lee, Chem. Phys. Lett. 438(4-6), 279-284 (2007).

21. J. Zhang, S. Wei, J. Lin, J. Luo, S. Liu, H. Song, and C. Tang, J. Phys. Chem. B 110(43), 21680-21683 (2006).

22. H. Y. Zhu, X. P. Gao, D. Y. Song, Y. Q. Bai, S. P. Ringer, Z. Gao, and R. L. Frost, J. Phys. Chem. B 108(14), 4245-4247 (2004).

23. H. W. Hou, Y. Xie, Q. Yang, Q. X. Guo, and C. R. Tan, Nanotech. 16(6), 741-745 (2005).

24. Y. Liu, D. Ma, X. Han, X. Bao, W. Frandsen, D. Wang, and D. Su, Mater. Lett. 62(8-9), 1297-1301 (2008).

25. W. Jing, S. Jun, X. and Bing, Effect of precursors on the morphology of hydroxyl aluminum prepared by hydrothermal treatment, Adv. Mater. Res. 308, 542-547 (2011).

26. Y. Chen, T. Zhou, H. Fang, S. Li, Y. Yao, and Y. He, Proc. Eng. 102, 388-394 (2015).

27. R. Giorgi, C. Bozzi, L. Dei, C. Gabbiani, B. W. Ninham, and P. Baglioni, Langmuir 21(18), 8495-8501 (2005).

28. P. S. Das, A. Dey, A. K. Mandal, N. Dey, and A. K. Mukhopadhyay, J. Adv. Ceramics 2(2), 173-179 (2013).

29. H. Dhaouadi, H. Chaabane, and F. Touati, Nano-Micro Lett. 3(3), 153-159 (2011).

30. S. O. Kazantsev, A. N. Fomenko, M. S. Korovin, E. A. Glazkova, A. S. Lozhkomoev, M. I. Lerner, and S. G. Psakhie, AIP Conf. Proc. 1683, 020080 (2015).

31. A. N. Fomenko, M. S. Korovin, O. V. Bakina, S. O. Kazantsev, E. A. Glazkova, N. V. Svarovskaya, and A. S. Lozhkomoev, AIP Conf. Proc. 1683, 020054 (2015).

32. A. S. Lozhkomoev, M. I. Lerner, A. A. Tsukanov, S. O. Kazantsev, O. V. Bakina, and S. G. Psakhie, Phys. Mesomech. 20 (2017).

33. Y. Zhang, L. Ren, M. Li, X. Lin, H. Zhao, and K. Yang, J. Mater. Sci. Technol. 28(9), 769-772 (2012).

34. M. Li, L. Ren, L. Li, P. He, G. Lan, Y. Zhang, and K. Yang, J. Mater. Sci. Technol. 30(9), 888-893 (2014).

35. A. A. Tsukanov and S. G. Psakhie, Sci. Rep. 6, 19986 (2016).

36. M. D. Sacks and T. Y. Tseng, J. Am. Ceram. Soc. 67(8), 526-532 (1984).

37. E. A. Barringer and H. K. Bowen, J. Am. Ceram. Soc. 65(12), 199-201 (1982).

38. K. Uchiyama, T. Ogihara, T. Ikemoto, N. Mizutani, and M. Kato, J. Mater. Sci. 22(12), 4343-4347 (1987).

39. R. Salmon and E. Matijević, Ceramics Int. 16(3), 157-163 (1990).

40. S. Zhang, J. Li, G. Lykotrafitis, G. Bao, and S. Suresh, Adv. Mater. 21, 419-424 (2009).

41. W. Jiang, B. Y. S. Kim, J. T. Rutka, and W. C. W. Chan, Nat. Nanotech. 3, 145-150 (2008). 